\title{
PRAGMATIC AND STYLISTIC ASPECTS OF EXPRESSING TOLERANCE IN MODERN AMERICAN SHORT STORIES
}

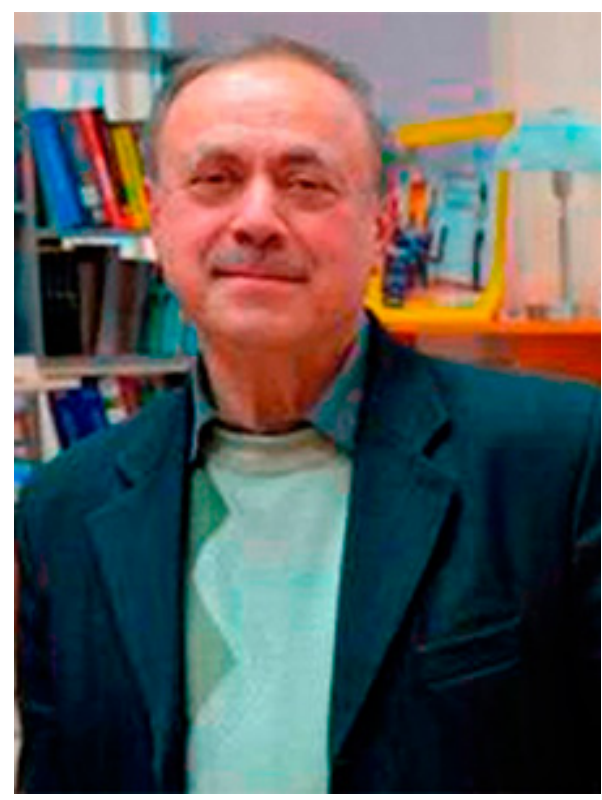

\author{
@ Alexander YEMETS \\ PhD in Philology, Associate Professor \\ Department of German Philology and Translation \\ Studies \\ Khmelnytsky National University \\ 11, Instytutska str., Khmelnytsky, 29016, UKRAINE \\ e-mail:yemetsov@ukr.net
}

ORCID: 0000-0001-6332-2830

\section{Abstract}

In the article, the aspects and types of such stylistic device as foregrounding are investigated in the short stories of contemporary American writers. The quantitative aspect of foregrounding prevails in flash fiction stories which is realized by means of stylistic convergence and parallelism. Convergences are mainly used in strong positions, especially in the endings, as in the stories by J. Updike, D. Galef, D. Eggers. The qualitative aspect of foregrounding is expressed with the help of tropes such as metaphor, simile and oxymoron which are also present in strong positions - titles, beginnings, endings (the stories by G. Paley, D. Galef, J. Updike). The idea of tolerance, sympathy, understanding is dominant in many flash fiction stories. Foregrounding, especially in the strong positions of the stories, emphasizes this idea, thus producing a strong pragmatic, emotional effect. Due to such device in the endings many flash fiction stories can be called modern parables of life, love, justice.

Keywords: foregrounding, flash fiction, strong position, convergence, tolerance.

Stylistics is a classical linguistic science which has its roots to ancient rhetoric. At the same time stylistics is a dynamically developing modern science. There can be at 
least two major reasons of popularity and significance of stylistics. Firstly as Beatrix Busse (Busse, 2010: 33) notes, the last decade has seen a further division of stylistics into such branches as cognitive stylistics, multimodal stylistics, corpus stylistics. Moreover, actually stylistics gave birth to the development of cognitive linguistics thanks to the fundamental book "Metaphors We Live By" written by George Lacoff and Mark Johnson. Also, cognitive poetics which developed as a branch of stylistics is now becoming an independent field of research due to the investigations by Peter Stockwell, as well as by the Ukrainian stylisticians Olga Vorobyova and Larisa Belekhova.

Secondly, stylistics possesses fundamental theoretical basis which enables to analyze new linguistic phenomena in such spheres as advertising, the language of the Internet, to say nothing of modern fiction and mass media articles.

According to the definition of Beatrix Busse and Dan Mc Intyre, "stylistics in its most general sense is the study of style in language and how this results from the intralinguistic features of a text in relation to non-linguistic factors such as author, genre, historical period, and so on" (Busse, 2010: 6). In reference to literary texts, Geoffrey Leech (Leech, 2010: 18) characterizes stylistics as the analysis of literary texts, using linguistic techniques. In such case we can speak about stylistics of literary texts (or fiction). As Mick Short (Short, 1996: 1) justly says, "Stylistics can sometimes look like either linguistics or literary criticism, depending upon where you are standing when you are looking at it”. Actually, literary stylistics is a bridge between literature and linguistics.

One the foundations of stylistics is the theory of foregrounding. The term is borrowed from art criticism, in particular the art of painting. The foreground is such part of a painting which is in the centre, which is the most prominent part of the work of art. The Russian formalists (R. Jakobson, V. Shklovsky) and the Prague school of linguistics (J. Mukarjovsky) formulated the principle of making some part of the literary text noticeable. The terms used were "vydvyzheniye" and later "aktualisace", which was translated by P. Garvin in 1960s as "foregrounding". The theory of foregrounding was suggested as a means of explaining the difference between poetic and everyday language.

The leading stylisticians gave different definitions of foregrounding. Irina Arnold suggests a more general definition: "Foregrounding is the ways of the text organization which focus the reader's attention of certain elements of the message" (Арнольд, 2004: 99). In our opinion, in this definition the word "certain” should be replaced by "important” or "pragmatically important” (elements). The writer's aim 
can be attracting attention to what is significant, special for the text interpretation and understanding.

John Doughwaite (Doughwaite, 2000: 93) gives a more detailed definition of foregrounding: "Foregrounding is the general linguistic technique by which a marked linguistic expression is produced in order to make that expression convey a different meaning that its synonymic, equivalent unmarked construction would have conveyed". Of course, the selection of the type(s) of foregrounding depends of the writer's individual style as well as the genre of the literary texts.

There are two approaches to the classification of the types of foregrounding. The first is suggested by Geoffrey Leech (Leech, 2007: 38) and involves the division into qualitative and quantitative aspects of foregrounding. The qualitative aspect is deviation from the language code itself, a break of some rule. The quantitative aspect involves the deviation of some expected frequency (Leech, 2007: 39). The qualitative aspect can be realized by different types of original tropes, such as metaphors, hyperboles, oxymora, and lexical devices, such as neologisms. As for the quantitative aspect, it can manifest itself in repetitions - lexical, phonetical, syntactical. Our previous investigation (Yemets, 2017: 102) revealed that stylistic convergences and parallelism are the most explicit examples of the quantitative aspect of foregrounding. According to the definition of Michael Riffaterre (Riffaterre, 1967: 432) stylistic convergence is the accumulation of stylistic devices which add expressiveness to each other. Convergences can include the combination of tropes, phonetical repetitions, syntactical structures, usually concentrated in a text fragment. The combination of stylistic devices in convergences is predetermined by the author's individual style and the pragmatic aim.

The second approach involves determining the particular types of foregrounding. Irina Arnold unites the most famous stylistic devices and suggests that there are three major types of foregrounding: 1) the effect of defeated expectancy; 2) coupling; 3) stylistic convergence (Арнольд, 2004: 100-112). At the same time Mick Short (Short, 1996: 10-14) singles out two types of foregrounding: parallelism and deviation. Deviation is understood as the change of literary norms, the creation of unusual linguistic form.

The two classifications have much in common. Parallelism and coupling denote the same linguistic phenomena - the use of the same or similar language units in similar positions. The effect of defeated expectancy (or anticipation) formulated by Roman Jakobson can be produced by different types of deviation, especially lexical deviation, the examples can be a famous word manunkind created by 
E. E. Cummings or the title of the poem "Peoplization of America" by A. Lawrence which was devoted to the tragic events of September 11, 2001. In general, the effect of defeated expectancy is wider and can be observed in the unpredictable endings of anecdotes or detective novels.

The only difference in two approaches is the device of stylistic convergence. In our opinion, some other devices can be added to this list, in particular allusions. Allusions are especially foregrounded when used in the so-called strong positions (titles, beginnings or endings) or throughout the text, systematically, as in the stories by Ray Bradbury “There Will Come Soft Rains”, “And the Moon Be Still as Bright”, in the novel by M. H. Clark "No Place Like Home". The use of rhythm in prose, alliteration can also produce the effect of foregrounding, but these stylistic devices can be referred to as the manifestations of parallelism.

Another significant factor in the investigation of foregrounding is the position of the foregrounded elements in the literary text. When convergence, parallelism, different types of deviation are used in such strong positions as the beginning and/or the ending, it gives special emphasis to these text fragments. It is also necessary to investigate the connection between the foregrounded parts of the text. Such strategy of linking together foregrounded features was called by Geoffrey Leech (1970: 120) the cohesion of foregrounding. "Foregrounded features are those parts of the text which the author, consciously or unconsciously, is signaling as crucial to our understanding what he has written" (Short, 1996: 36).

In our investigation of foregrounding in literary texts we will apply the principles of analysis suggested by John Doughwaite. The process of interpreting includes three stages: 1) recognizing a foregrounded element; 2) identifying the linguistic nature of the foregrounding technique employed; 3 ) interpreting the type of foregrounding in context (Doughwaite, 2000: 93).

It is possible to say that the American prose fiction in the early 21st century reveals a clear tendency to shorter stories. Actually, it continues the tendency of the 20th century with short-short stories, sudden fiction and, more recently, flash fiction. Flash fiction stories can be regarded as the concentrated manifestation of the abovementioned tendency. Three collections of flash fiction have been published in the USA and one in Australia - in 1992, 2006, 2015. The collection "Flash Fiction Forward" includes the stories of American writers, among them such famous names as John Updike, Grace Paley, Don Shea. The 2015 collection "Flash Fiction International" contains the stories of writers from different countries of the world. 
Because of the small size of flash fiction stories the effect of foregrounding in these texts can be more noticeable. At the same the major function of foregrounding in literary texts can be not only attracting attention, but emphasizing the main fragments, producing pragmatic effect on the reader.

Our investigation of the flash fiction stories published after the year 2000 enabled to reveal one of the main ideas in these texts - the idea of tolerance.

Therefore, the aim of this paper is to determine the types of foregrounding in flash fiction stories and how foregrounding helps to express the idea of tolerance in these texts. It is necessary to say that the authors of flash fiction make use of different techniques of foregrounding. However, one common feature is the position of the foregrounded elements in these texts. As a whole, it is one strong position - the ending. The second common feature is that the major type of foregrounding in the endings of many short stories of this genre is stylistic convergence.

It should be noted that while deviation in literary and advertising texts has been analyzed by such prominent linguists as M. Short, G. Leech, J. Doughwaite and others, the linguistic nature of convergence and the characteristics of its components have not received sufficient attention. Therefore, the novelty of our paper lies in the detailed description of stylistic convergence in the short stories of modern American writers and the pragmatic effect produced by this stylistic device.

Our investigation included the story "Zoo" by Edward Hoch, two stories by Don Shea "Jumper Down” and "Black Friday", the story "Oliver's Evolution” by the outstanding writer John Updike, the story "Justice - A Beginning" by a well-known writer Grace Paley, the stories "My Date with Neanderthal Woman” by David Galef, "Bullhead" by Leigh Wilson, "Accident” by Dave Eggers and a number of other stories. The texts are different in the plot, in the description of characters, but what unites the stories is the idea of sympathy and tolerance. In general, several aspects of tolerance can be identified in the stories: 1) racial tolerance; 2) cultural; 3) age tolerance; 4) financial; 5) tolerance to people in tragic situations. Of course, such classification seems approximate and does not fully reflect the writers' ideas, but it could help better understand the pragmatic aims of the authors and find common features of the stories.

The story "Zoo" by Edward Hoch is one of the most exciting short stories in the last two decades because of its brevity and the depth of the author's intention. Externally, it looks like a science fiction story. The spaceship of Professor Hugo brings to Earth the interplanetary zoo. So the people of Earth, after paying one dollar, could observe 
strange creatures - three-legged creatures from Venus, snakelike horrors from other planets and, especially interesting, "the little known horse-spider people from Kaan" (ES: 63). The first type of foregrounding includes lexical deviation (horse - like spiders). The description of these and other creatures is made by means predominantly negatively colored lexical units: awe; horrors; wild breed of nightmare; horrified.

The story is divided into two parts. The first part ends with the phrase: "The Earth peoples agreed that this has been the very best Zoo yet”. In the second part it is described how the horse-spider people returned to their native planet Kaan and shared their opinion about their visit to Earth. The little one said: "On the place called Earth it was the best. The creatures there wear garments over their skins, and they walk on two legs. $\langle\ldots>$ It was the very best Zoo yet” (ES: 63-64). Thus, the two strong positions of two parts are connected by repetitions, creating distant cohesion. The structure of the story is based on reverse parallelism: for the Earth people horsespiders are a zoo, for horse-spiders the people of Earth represent a zoo. Thus, parallelism represents a type of foregrounding. The main idea, in our interpretation, is expressed implicitly - despite the differences in appearance, behavior, manners, the living creatures should respect each other, treat each other as equal, not as monsters. It should be noted that the title word zoo is used without any article, which can be interpreted as a universal term, a global metaphor of alienation which should be rejected as it foregrounds the idea of enmity. In the process of discussion and translation of the title with my senior students we had different variants of the title in the target language: звіринець; зоопарк; зоосад. The word звіринеиь in translation was rejected, and the variant зоопарк was chosen, as a more positive, more tolerant word.

The principle of cultural tolerance is clearly expressed in the story "My Date with Neanderthal Woman” by David Galef. The very title contains semantic deviation realized by a particular type of oxymoron. The idea seems impossible. Though Galef seriously describes how the TransWorld Dating Agency organized such date.

The major stylistic device of foregrounding in the story is antithesis. The author frequently shows the contrast, the difference in culture, in appearance, in behavior between a modern man and a Neanderthal woman: "Her furry brown hair was matted with sweat; she rubbed her belly; the little loincloth Glena wore made me feel overdressed. When I reached for her hand, she jerked back - different cultures have different intimacy rites” (FFF, 2006: 110-111). So, besides qualitative aspect of foregrounding, we can observe its quantitative aspect - the redundancy of antithesis. 
The quantitative aspect of foregrounding is brilliantly realized in the last strong position - the final paragraph where the author expresses the idea of mutual understanding and tolerance. The paragraph contains stylistic convergence which is small in size but includes parallel structures, play of words, metaphor and antithesis: "Yes, I know all the objections. Some couples are separated by decades, but we're separated by millennia. I like rock music and she likes the music of rocks. I'm modern Homo Sapiens and she's Neanderthal, but I think we can work out differences if we try" (FFF, 2006: 111).

So, in the stories "Zoo" and "My Date" the idea of tolerance, of mutual respect is expressed in different ways. In "My Date" it is realized explicitly, while in "Zoo" such pragmatic idea is implicit, and the interpretation depends on the reader's literary background and point of view.

Age difference can also become the basis for expressing the idea of tolerance. In the text "Justice - A Beginning” by Grace Paley the narrator is a woman, a member of the jury in court. She cannot help feeling sympathy for an elderly woman, the mother of the defendant. The man committed a crime - robbed the old grocer with a real gun. But the mother's sufferings touch the woman's heart. Faith describes the woman as a dying flower: "She leaned on the witness bar, her face like a dying flower in its lateseason, lank leafage of yellow hair, turning one way then the other in the breeze and blast of justice. Like a sunflower maybe in mid-autumn, having given up on the sun, Faith thought, letting wind and weather move her heavy head” (FFF, 2006: 124). Here we can see the realization of the quantitative aspect of foregrounding - the stylistic convergence in the strong position, in the very beginning of the story, can produce a strong pragmatic effect on the reader. The convergence includes two original similes extended by metaphors, alliterations which give poeticalness to the fragment.

In another story, "Bullhead" by Leigh Wilson, the idea of tolerance is combined with the feelings of pity, sympathy and understanding of the daughter to her mother. When the mother tells her a story about the love of her life she always cries. And once a year the mother rents a boat and goes out on the lake that drowned her hometown during the construction of the dam. She drops a coin in the water, just over the place, where her old house must be. In this house, in the bedroom the mother of the narrator made love with the boy next door, the love of her life. Later the boy moved with his family to Texas, and the mother never saw him. But the mother, a married woman with children, still remembers him and goes to the lake. She drops a coin as a symbol of memory, fifty years - fifty coins. 
Both qualitative and quantitative aspects of foregrounding are realized in the story. The qualitative aspect is expressed by oxymoron in two strong positions - the beginning and the ending: "Every story is true and a lie. The use of this frame repetition not only creates cohesion in the text but also emphasizes the main idea expressed in the last paragraph: Every story is true and a lie. The true part of this one is: Love and the memory of love can't be drowned. The lie part is that this is good thing” (FFF, 2006: 100). The quantitative aspect is realized by stylistic convergence consisting of oxymoron, metaphor (love), parallel constructions and antithesis. The paradoxical phrase about the truth and lie in every story can be interpreted as the contradictory attitude to such memory of love - tolerance, sympathy and at the same time disapproval.

The tolerant attitude of people in everyday situations, in particular in conflict, is described in the short story "Accident” by Dave Eggers. The main character has a road accident, and the accident is his fault. He damages a car with three teenagers. Nobody is hurt, but the car is wrecked. The driver expects aggressive, violent reaction from teenagers, but they are quiet and tolerant. The teenagers understand his mistake and are ready to forgive him. The man is so touched that he wants to cry: "You want to fall on him weeping, because you so lonely, so lonely always, and all contact is contact, and all contact makes us so grateful we want to cry and dance and cry and cry”. This stylistic convergence which produces a considerable emotional effect due to lexical and syntactic repetitions continues in the final paragraph: "In a moment of clarity, you finally understand why boxers, who want so badly to hurt each other, can rest their heads on the shoulders of their opponents, can lean against one another like tired lovers, so thankful for a moment of peace” (FFF, 2006: 102).

In this story a seemingly everyday trivial situation is foregrounded by means of the unusual extended simile. Due to the convergence the accident becomes some generalization of the possibility of reconciling, of mutual understanding and, probably, forgiveness.

The tolerance and sympathy to people in difficult financial situations can be observed in the stories by Andrew McCuaig and Don Shea. The story "The Wallet" by A. McCuaig describes the situation in the gas station. A young woman drives to the station in a car and demands money. It looks like a robbery but the employee at the gas station, also a young woman, sees two small children in the backseat, their eyes wide and afraid. The driver looks very nervous, her face swollen and scarred, she is poorly dressed. And Elaine, the employee, feels sudden pity and sympathy to this woman and gives her the wallet with ninety-two dollars. As distinct from other 
stories, the foregrounded element is the simile in the last sentence: "The older girl's face, framed by the back window, receded into the darkness, her eyes like glowing stones“ (FFF, 2006: 132). This phrase in the strong position can be interpreted as the hope for a happier future for the children and their mother, their gratitude.

The sympathy for the person in need, in difficult financial situation is foregrounded in "Black Friday" by Don Shea. It is a tragic story of a man who was jobless for some time and very upset with such situation. He was ready for any job and at last he found a minimum wage job in the local megastore. Everything went well but one day of bargain sales known as Black Friday the man was trampled to death by a big crowd of shoppers. In this text we can observe the quantitative aspect of foregrounding. First, it is realized in parallel constructions which emphasize the man's despair: "Everyone reads the letter. Everyone is polite. But everyone is cutting back or slowing down”. Secondly, foregrounding is realized in multiple lexical repetitions of the words job and work (10 times) and glove (15 times). The word glove is used throughout the text and becomes symbolic. The man found the job and he could afford to buy a glove, a baseball glove for his son: You love your son and he loves baseball. You want to give him a baseball glove for Christmas, a quality glove, a grownup glove he will have for a long time. When the man dies a middle-aged saleswoman finds this glove in a bag under her counter. She understands whose glove it was, hesitates, but then decides to give the glove to her son as a Christmas present.

The glove becomes the symbol of father's (mother's) love. It is interesting to note that in some context the words glove and love are used in close contact creating some cohesion and a kind of stylistic paronomasia.

In another story "Jumper Down" Don Shea describes a tragic situation. The main character Henry works as a paramedic. His job is to save people who want to commit suicide jumping from of one of the bridges in New York. Therefore, Henry is called “jumper up expert”. One day, on his last shift before retiring, he receives a call that a man is going to jump from the Brooklyn Bridge. When the paramedics came the man had already jumped and hit the ground. Henry decided to support the man, telling him the words of consolation: "I just gotta tellya, I wanted you to know, that jump was fucking magnificent!" The effect of foregrounding in this utterance is created by deviation - the vulgar word fucking as an intensifier and the epithet magnificent which seems rather paradoxical in the situation. The quantitative aspect of foregrounding is actualized in the last paragraph where the narrator makes the explicit conclusion: "I mean it was clearly not the occasion to admonish the jumper, who had suffered enough defeats and rejections in his life. Seems to me if I was a 
jumper on the way out, right out there on the ragged edge of big mystery, I might, indeed, upon my exit, find some last modicum of comfort in Henry's words, human words of recognition and congratulation" (FFF, 2006: 19). The convergence in this strong position is particularly significant, as it represents the author's position, the attitude to people with tragic fate, his sympathy and tolerance. While this convergence is not so abundant in stylistic devices (metaphor, antithesis, syntactical repetitions), it is very emotional and touching.

In the newest collection of flash fiction stories "Flash Fiction International" (2015) many texts are devoted to the problem of solitude. Foregrounding is mainly realized by parallel constructions and lexical or stylistic repetitions, convergence is seldom used. The story "Farewell, I Love You and Goodbye" by James Tate begins with parallelism in such strong position as the beginning: Our lives go on. Our fathers die. Our daughters run away. Our wives leave us. And still we go on (FFI, 2015: 193). Despite this pessimistic and philosophical reflection, the main character looks for a beloved woman, tries to create a family. In the short story "The Nihilist" by Ron Carlson, the famous American writer, we can also observe the quantitative aspect of foregrounding which is manifested in multiple repetitions of the word care (both a noun and a verb). The text represents an inner monologue of the main character who struggles with his own nihilism, indifference to life and people but who badly wants care, sympathy, love: "Your heart, he said. Who cares? Who fucking cares; <...>. His nihilism was fraudulent. He cared about too much; $\langle\ldots$. . He wanted care in his life. He exhibited care. He was capable of it” (FFI, 2015: 193-194). In these two stories by R. Carlson and J. Tate and in several other flash fiction stories the theme of loneliness is foregrounded. However, implicitly, the authors' attitude to their characters can be interpreted as sympathy, tolerance to their failures and drawbacks.

In conclusion of our investigation of foregrounding it can be stated that the quantitative aspect of this device is dominant in contemporary flash fiction stories. Foregrounding is realized by means of stylistic convergences in the strong positions, especially in the endings. Convergences are not big in size and, as a rule, are tropeicsyntactic, with tropes and antithesis. The presence of convergences in the final positions reflects the authors' viewpoints and attitude to reality, to their characters and can produce a considerable pragmatic effect (the stories by L. Wilson, D. Galef, J. Updike, D. Shea). Due to such stylistic devices and pragmatic effect most analyzed stories can be characterized as modern parables, parables of love, life, happiness. Parallelism and multiple lexical repetitions (the works by G. Paley, R. Carlson) also 
represent the quantitative aspect of foregrounding and emphasize the leitmotif of these texts.

The qualitative aspect of foregrounding is expressed by oxymora in the title (D. Galef) and the strong positions (G. Paley, L. Wilson, D. Eggers) and renders emotional coloring to the texts.

The idea of tolerance, sympathy, understanding is brilliantly expressed in most stories. The tolerance to people (creatures) of different race, culture is foregrounded in the stories by E. Hoch and D. Galef, the tolerance to people of old age is expressed in the stories of L. Wilson, G. Paley, the tolerance to people in difficult situations (poverty, accident, suicide) is expressed very emotionally in the texts by D. Eggers, D. Shea, A. McCuaig. The fact that contemporary American writers express this idea in their stories of flash fiction can be one of the reasons of the popularity and importance of this prose genre in the literature of the 21st century.

Submitted on 31 May 2018.

\section{References}

Арнольд, И. В. (2004). Стилистика. Современный английский язык. М.: Флинта: Наука.

Busse, B. and McIntyre, D. (2010). Language, Literature and Stylistics. In: Language and Style. In Honour of Mick Short. London: Palgrave Macmillan.

Doughwaite, J. (2000). Towards a Linguistic Theory of Foregrounding. Alessandria: Edizion’ dell’Orso.

Leech, G and Short, M. (2007). Style in Fiction. A Linguistic Introduction to English Fictional Prose. London: Pearson Education.

Short, M. (1996). Exploring the Language of Poems, Plays and Prose. London: Longman.

Yemets, A. (2017). The role of stylistic convergence in the contemporary American fiction. Modern Science / Moderni Veda, 7, pp. 102-108.

\section{Literary Illustrations}

FFF Flash Fiction Forward (2006). ed. by Thomas, J. and Shapard, R. New York - London: W. W. Norton \& Company.

FFI Flash Fiction International (2015). ed. by Thomas, J. and Shapard, R. and Merril, C. New York - London: W. W. Norton \& Company. 